\title{
Design of Experimental Suspended Footbridge with Deck Made of UHPC
}

\author{
Marek Blank ${ }^{1}$, Petr Tej ${ }^{1}$, J. Kolísko ${ }^{1}$ and L. Vráblik ${ }^{2}$ \\ ${ }^{1}$ Klokner Institute, Czech Technical University in Prague \\ ${ }^{2}$ Faculty of Civil Engineering, Czech Technical University in Prague
}

\begin{abstract}
This paper deals with the static and dynamic design of experimental footbridge for pedestrians and cyclists in the municipality Lužec nad Vltavou in Czech Republic, Europe. This work aims to familiarize the reader with calculations carried out and the results obtained, describing the static and dynamic properties of proposed footbridge. The construction of footbridge is designed as a suspended structure with prestressed bridge deck consisting of prefabricated UHPC panels and reversed "V" shaped steel pylon with height of approximately 40 meters. The deck is anchored using 24 steel hangers in one row in a steel pylon - 17 ropes in the main span and 7 cables on the other side. Range of the main span is 99.18 meters and the secondary span is $31.9 \mathrm{~m}$. Deck width is 4.5 meters with 3.0 meters passing space. The bridge is designed for the possibility of passage of vehicles weighting up to 3.5 tons. Deck panels are made of UHPC with reinforcement. At the edge of the bridge on the side of the shorter span the bridge deck is firmly connected with abutment and on the other deck it is stored using a pair of sliding bearings. The utilization of the excellent properties of UHPC allows to design a very thin and lightweight construction of the deck, which could not be achieved with the use of normal concrete.
\end{abstract}

\section{Introduction}

The footbridge transfers the bike path and the pedestrian trail over the river Vltava, connecting the village Lužec nad Vltavou with surrounding municipalities on the other side of the river. This footbridge will permanently replace current ferry.

The structural design according to various requirements and basic static and dynamic analysis of the structure were performed and all kinds of load regarding the nature of the structure were considered.

\section{Materials}

Ultra High Performance Concrete - UHPC is a new cementitious composite material, which is mainly used for reducing or optimizing a weight and dimensions of structures. Its outstanding features, mainly high compressive strength $(>150 \mathrm{MPa})$, high tensile strength $(>10 \mathrm{MPa})$ and high durability, are generally known [1][2][3]. UHPC is a homogenous material whose mixture consists of very fine aggregates, cement, fine fillers (silica fume, fly ash), superplasticizers and randomly distributed fibres (steel, glass, polymer). A very low water-cement ratio and a fine grained mixture provide extremely low porosity [3].

\section{Structural Design}

The axis of the bridge leads over the river bed in approximately perpendicular direction and at the end of the bridge, on the shorter span side, passes in earth ramp located partly in a left curve of radius 30.0 meters for the connection to the existing road. Access ramps on both sides are sufficiently dimensioned to flood protection measures, but they are also made in the minimum slopes and equipped grassy vegetation in accordance with the landscape character of its surroundings.

The bridge deck height is kept in top curved surface of radius 777.5 meters. This ensures enough camber of the footbridge over the rivers canaliculate profile measuring 35.0 meters with height of 7.0 meters, which was necessary due to the requirement of waterway administrator. The rise of an arch is chosen so that the ends of the supporting structure would still have the maximum allowed slope for wheelchair use of the building.

The supporting structure consists of panels stapled to the contact joint by prestressed rods and cables. Pretension leads in outer beams with the width of 0.75 meters and a thickness of approximately 0.3 meters. These beams are connected by desk with at least $60 \mathrm{~mm}$ thickness, which forms a walk-bearing surface. The surface of this area is fitted with sprayed anti-slip insulation finish in natural color of the original UHPC material. Each panel is reinforced by a pair of ribs located in about $1 / 4$ the length of the panel from each end. The utilization of the excellent properties of UHPC allows to design a very thin and lightweight construction of the 
deck, which could not be achieved with the use of normal concrete [4-9].

Each panel contains an embedded steel weldment at a distance of 1.25 meters from the end of the panel, in which will be anchored the hanging rope. The total length of the panels is $5.65 \mathrm{~m}$. End panels of the deck will be accompanied by a monolithic part for the realization of the restraint (connection of the bridge deck and abutments) and for the installation of bridge bearings and the expansion joint on the opposite side of the bridge. The deck therefore dilates its entire length to the one abutment. Dewatering of the bridge is provided by a free water drain from the surface. The deck will be illuminated by spotlights mounted in the construction of the railing, which has the height of 1.3 meters.

\section{Static Design}

Basic static scheme of the footbridge is formed by a beam suspended by rope elements (able to transmit only tension force) into the steel pylon, while the last hanger on the side of the shorter span is anchored to the abutment outside the supporting structure. On this side is the desk cantilevered to the abutment, which positively influences the dynamic properties of the system. On the opposite side is the structure deposited on the sliding joints (bearings) that allow the dilation of the structure. Computing model was created in Scia Engineer 2014, Civil Midas and Midas FEA [10]. For the making of the model have been used 2D shell finite elements. The analysis was based on the basic principle of the hangers acting as elements with a sagging which axial stiffness is affected by the magnitude of a tensile force. The calculation is, given the nature of the construction, materially and physically nonlinear.

The structure is loaded by permanent and variable load effects. Permanent loads include the self-weight of the construction and all additionally built parts. Variable loads represent loads caused by traffic on the bridge pedestrians, vehicles up to 3.5 tons, and climatic loads wind, snow and temperature. Pedestrian movement on the structure is simulated by moving surface load with size of $4.0 \mathrm{kN} / \mathrm{m}^{2}$ and vehicle load is represented by moving two axle vehicles of total weight of 3.5 tons. Both loads are considered in the model so that their effect would be maximal due to the monitored variable - thus unloading effects are neglected.

Within the primary static calculation was mainly controlled the extreme normal stress at crucial parts of the structure to maintain the pressure reserve and tension in the walls of the pylon. Furthermore, the stability of the controlled compression of the steel pylon and two fundamental methods - Euler's concept of stability and the introduction of production inaccuracies into the shape the pylon. The result of the calculation was the need to fill the foot of the pylon with concrete to reduce the otherwise high number of reinforcements and prevent buckling of the walls. Further was also observed the deformation of the structure, taking into consideration that all shifts and deflections caused by the self-weight of the structure will be removed by the camber and simultaneously by prestressing of the hangers (refer to Fig. 1).

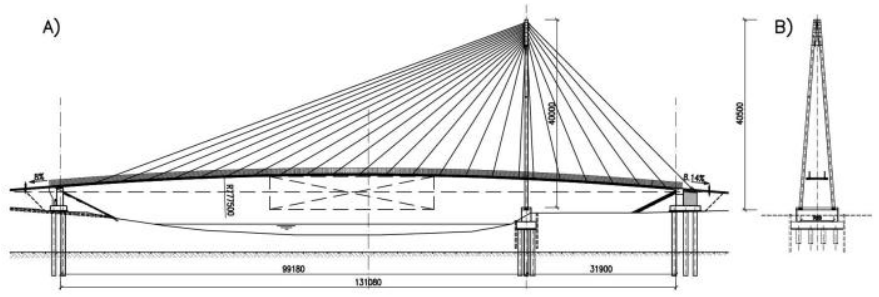

C)

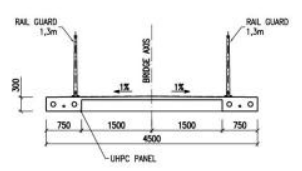

Figure 1. - A) Typical Cross-Section of the Deck, B) Longitudinal Section, C) Cross-Section.

At the very hangers occurs reducing of their axial stiffness due to their elongation. Introduced normal force is partially depleted by changing the geometry of the element until the moment when the cable is activated. From this point it can be assumed that the element behaves linearly and the full stiffness of the rope applies. This behavior is known as tension stiffening. Static design effort was to ensure such axial forces in the cables (by permanent loads, variable loads, but also the actual final tightening of the ropes) that during their minimal stress still remained sufficient tensile reserve in ropes, which would guarantee their linear behavior and thus the linear behavior of the structure. The model takes into account the influence of the construction process and the gradual tensioning hangers.

Tensioning of the cables, and the normal force in general applied in them has a beneficial effect of reducing tensile stresses arising in the deck of the footbridge from the extreme positions of the live load. Minimum required tensile strength, which ensures its linear behavior, was set for each rope by using the calculation based on its geometric characteristics. The effort is within the construction of the object to strain the ropes so that it acts almost linearly by minimizing their sag. From the static model, it is possible to determine that the ropes at the edge of the bridge on the side of his longer range will need to be prestressed, because of their angle does not allow the transfer of sufficient tensile normal force of self-weight of the structure to ensure their linear behavior (refer to Fig. 2, 3).

\section{Dynamic Design}

Basic static scheme of the footbridge is formed by a beam suspended by the rope elements (able to transmit only tension force) into the steel pylon, while the last curtain on the side of the shorter field is anchored to the abutment outside the supporting structure. On this side is the desk cantilevered to the abutment, which positively influences the dynamic properties of the system. On the opposite side is the structure deposited on the sliding 
joints (bearings) that allow the dilation of the structure. Computing model was created in Civil Midas and Midas FEA. For the making of the model have been used 2D shell finite elements. The calculation is, given the nature of the construction, materially and physically nonlinear.

Natural Frequencies and Mode Shapes of Proposed Structure are Listed below:

n. $1 \mathrm{f}=0,632-$ deck bend / $\mathrm{n} .2 \mathrm{f}=0,945-$ deck torsion / n. $3 \mathrm{f}=1,098-$ deck and pylon bend / n.4 f=1,508 - deck and pylon bend / $\mathrm{n} .5 \mathrm{f}=1,864$ - pylon bend / $\mathrm{n} .6 \mathrm{f}=1,949$ deck and pylon bend / n.7 f=1,955 - deck torsion and longitudinal pylon bend / $\mathrm{n} .8 \mathrm{f}=2,389-$ deck torsion and longitudinal pylon bend/ $\mathrm{n} .9 \mathrm{f}=2,758$ - deck and pylon bend / $\mathrm{n} .10 \mathrm{f}=2,981-$ deck torsion and longitudinal pylon bend (Fig. 4).

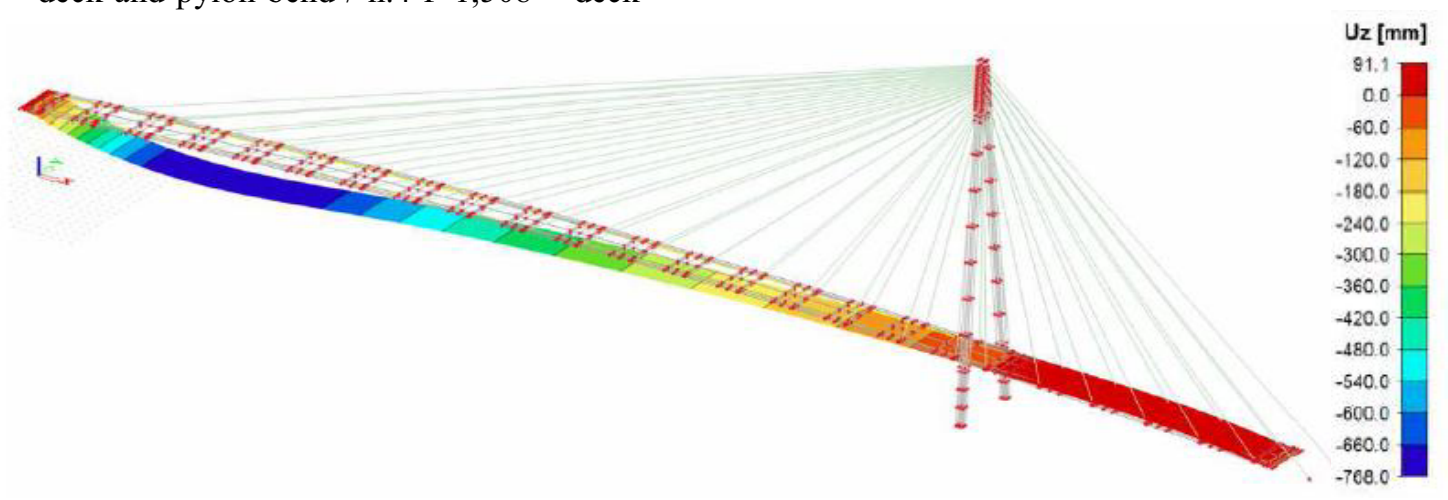

Figure 2. Vertical Deformation of the Deck

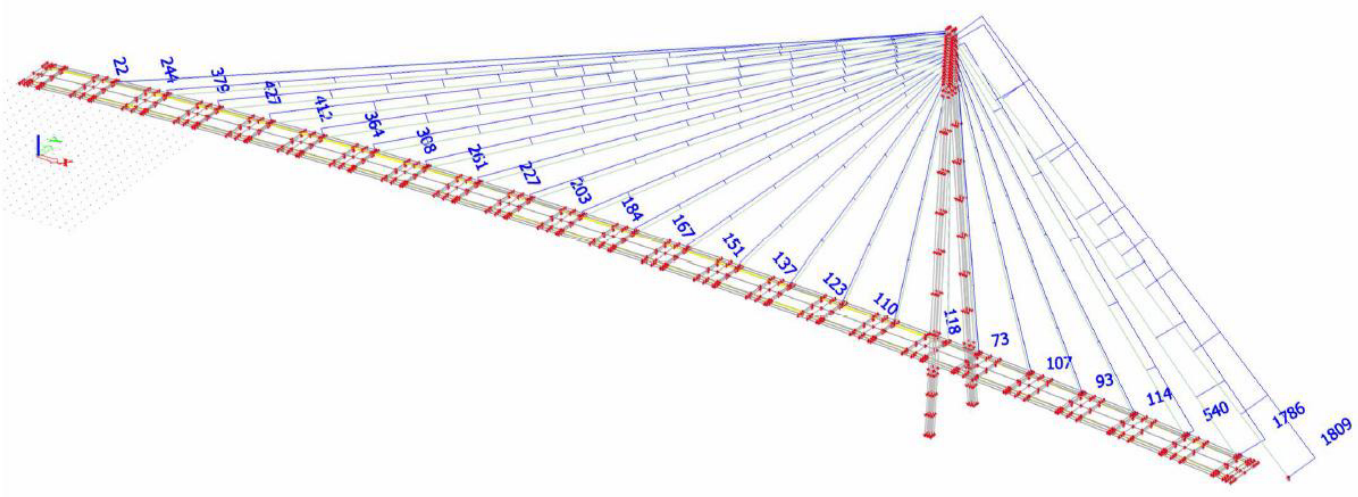

Figure 3. Normal forces in ropes from self-weight of the structure
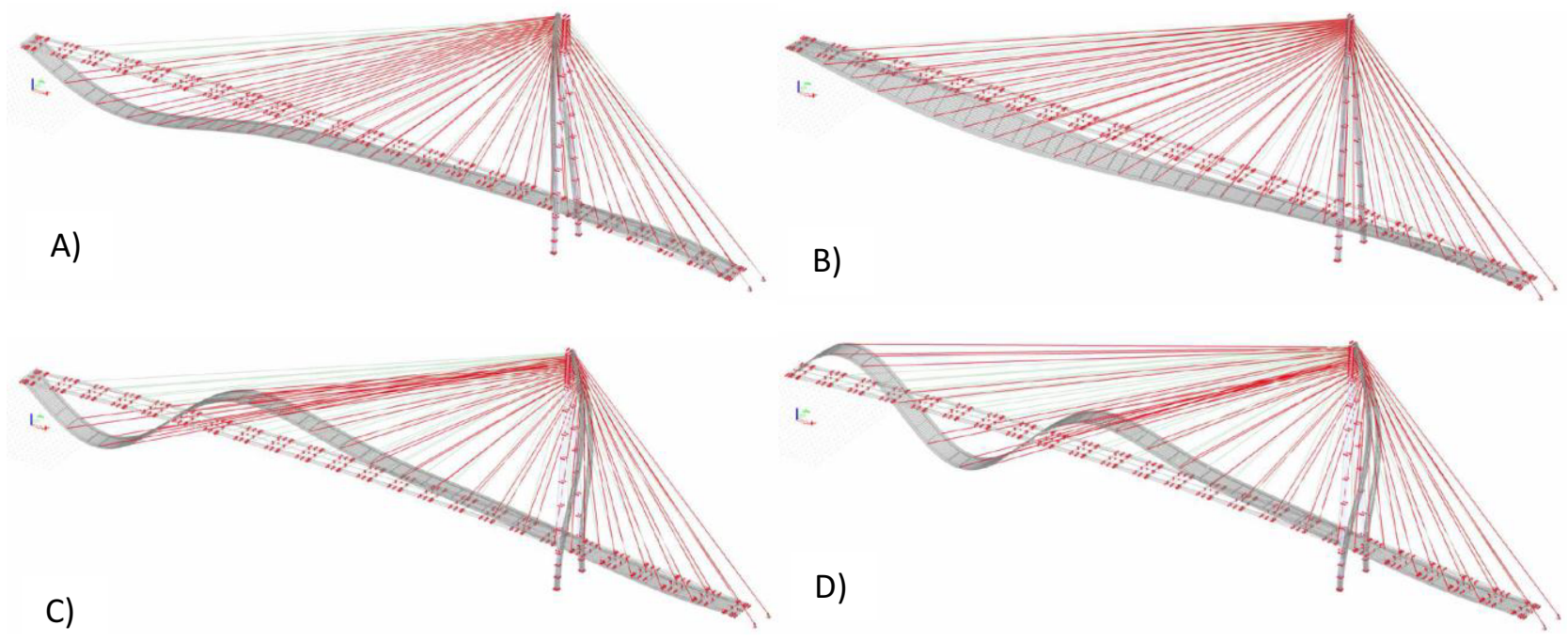

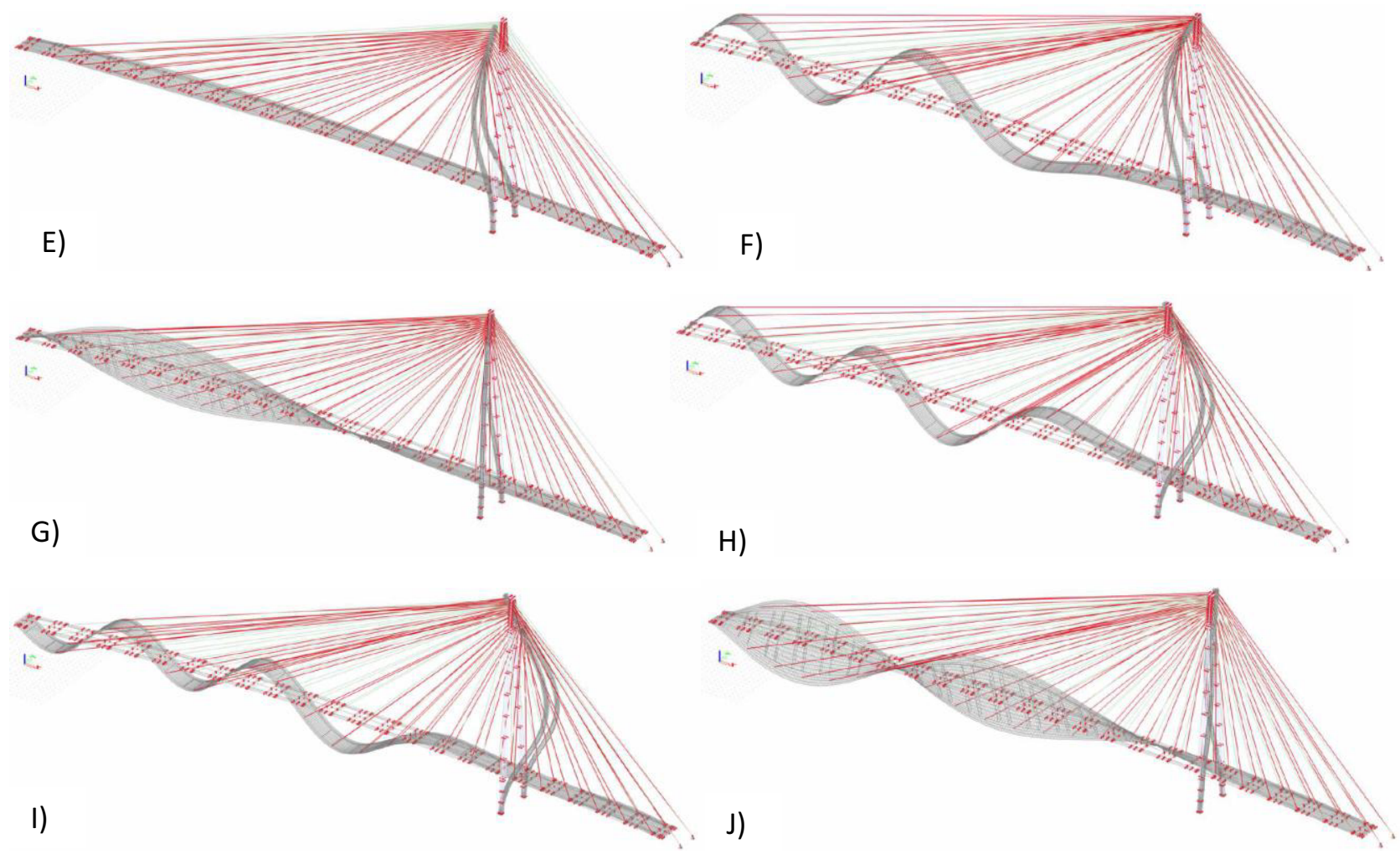

Figure 4. A) First mode shape, B) Second mode shape, C) Third mode shape, D) Fourth mode shape, E) Fifth mode shape, F) Sixth mode shape, G) Seventh mode shape, H) Eight mode shape, I) Ninth mode shape, J) Tenth mode shape

\section{Conclusions}

The basic static and dynamic analysis of the structure were performed and all kinds of load regarding the nature of the structure were considered. Due to the significant nonlinear behavior of components of the structure it was necessary to deal with the construction as a geometrically and physically nonlinear task.

Given the nature of the structure, it was made its basic modal analysis for the determination of natural frequencies and associated mode shapes. From the results it is possible to conclude the behavior of the structure and its response to load by pedestrians. With regard to the fact that it is a very lightweight construction, it is possible to predict from the modal analysis results, that after the dynamic load test (to determine the logarithmic decrement of attenuation) it will be necessary to fit a passive vibration damper on the construction, which will change the mass distribution on the structure.

The construction met all the criteria and it is possible to conclude, that the design is feasible and meets the requirements for this type of construction.

\section{Acknowledgement}

This research is supported by grant No. GAČR 15$2670 \mathrm{~S}$.

\section{References}

1. B. Graybeal, "Ultra-High Performance Concrete," FHWA Report HRT-11-038, March 2011

2. AFGC/SETRA; "Bétons fibrés à ultra-hautes performances. Recommandations." Documents scientifiques et techniques. Association Française de Génie Civil, Setra, Bagneux Codex, 2013.

3. JSCE-USC; "Recommendations for Design and Construction of Ultra-High Strength FiberReinforced Concrete Structures - Draft."

4. SETRA/AFGC: Ultra High Performance FibreReinforced Concretes: Interim Recommendations, $01 / 2002$.

5. AFGC/SETRA: Ultra High Performance FibreReinforced Concretes: Recommendations (06/2013). Paris CEDEX.

6. JSCE, Recommendations for Design and Construction of High Performance Fiber Reinforced Cement Composites with Multiple Fine Cracks, Rokugo K., (ed.) Concrete Eng. Series, 82, 2008.

7. Processings from HIPERMAT 3rd International symposium on UHPC and Nanotechnology for High Performance Material, Kassel, March 7-9,2012.

8. Kolísko, J., Rydval, M., Huňka, P. UHPC Assessing the Distribution of the Steel Fibre and Homogeneity of the Matrix. fib Symposium Tel Aviv, Tel Aviv, Israel. 2013. ISBN 978-965-92039$0-1$.

9. Paulík P.: The effect of curing conditions (in situ vs. laboratory) on compressive strength development of high strength concrete. Procedia Engineering, Vol. 65, 2013, Pages 113-119.

10. FIB Model Code for Concrete Structures 2010, C2013 fib, Ernst \& Sohn. 